\title{
Políticas habitacionais e a segregação socioespacial no Brasil: uma análise à luz do programa Minha Casa Minha Vida'
}

\section{Housing policies and socioespacial segregation in Brazil: an analysis of the light of the program Minha Casa Minha Vida}

\author{
Santos, Laini'; Martins, Isabela2; \\ ' Universidade Federal de Santa Catarina (UFSC), Rua Elaine Cristina, n514, \\ bairro Jardim Eldorado, Palhoça, Santa Catarina - Brasil. e-mail: \\ laine.souza20@gmail.com \\ 2 Universidade Federal de Santa Catarina (UFSC), e-mail: \\ isabela.bmart@gmail.com
}

\begin{abstract}
RESUMO
A estruturação das políticas públicas de habitação na história recente do Brasil está enraizada no contexto da desigualdade socioespacial e exclusão. Este estudo pretende discutir essa relação, por meio da implantação do Programa Minha Casa Minha Vida. É resultado de uma discussão teórica em fase concluída. Apesar desse tema ser recorrente nos estudos acadêmicos, como também em outros meios, acredita-se que ainda há espaços para discussões, pois é importante compreender a complexidade da questão da habitação, que não envolve apenas a moradia em si, mas também a propriedade fundiária e os sistemas de financiamento. Esta abordagem tornou-se possível através de pesquisas analíticas sobre o contexto. Percebeu-se que esse modelo de habitação reforça a segregação socioespacial imposta à população de baixa renda, uma vez que sustenta a instalação de moradias em áreas periféricas das cidades. A população economicamente vulnerável fica excluída da possibilidade de morar próximo às áreas onde se concentram a infraestrutura viária, transporte público, saneamento de qualidade, além da maior oferta de bens e serviços e oportunidades de emprego, para dar lugar a dinâmica do capital, que muitas vezes é amparado pela força que deveria legislar e garantir o bem-estar da nação.
\end{abstract}

Palavras-chave: Segregação socioespacial, Habitação social, Exclusão.

\begin{abstract}
The structuring of public housing policies in the recent history of Brazil is rooted in the context of socio-spatial inequality and exclusion. This study intends to discuss this relationship, through the implementation of the Minha Casa Minha Vida Program. It is the result of a theoretical discussion in the finished phase. Although this theme is recurrent in academic studies, as in other means, it is believed that there is still room for discussion, because it is important to understand the complexity of the housing issue, which involves not only housing itself, but also land ownership and financing systems. This approach has become possible through analytical

\footnotetext{
${ }^{1}$ SANTOS, Laini; MARTINS, Isabela. Políticas Habitacionais e Segregação Socioespacial no Brasil: uma análise à luz do Programa Minha Casa Minha Vida. In: II SIMPÓSIO NACIONAL DE GESTÃO E ENGENHARIA URBANA: SINGEURB, 2019, São Paulo. Anais... Porto Alegre: ANTAC, 2019.
} 
research on context. It was noticed that this housing model reinforces the socio-spatial segregation imposed on the low-income population, since it supports the installation of housing in peripheral areas of the cities. The economically vulnerable population is excluded from the possibility of living near areas where road infrastructure, public transportation, quality sanitation, and the greater supply of goods and services and employment opportunities are concentrated, to give rise to the dynamics of capital, which many supported by the force that should legislate and ensure the well-being of the nation.

Keywords: segregation; social habitation; exclusion.

\section{INTRODUÇÃO}

O contexto das políticas públicas voltadas à habitação de interesse social no Brasil passou por caminhos difíceis ao longo do seu desenvolvimento. Apesar do cenário desfavorável com grandes déficits habitacionais, a questão só começou a ser abordada a partir da década de 1940 e apresentar resultados significativos nos anos de 1980. Com todos os avanços e retrocessos o tema se expandiu às margens de duas lógicas: a capitalista versus a de exclusão.

Tomando tais premissas como direcionamento, este trabalho tem como objetivo analisar a evolução das políticas públicas habitacionais brasileiras, com destaque para a forma de implementação do Minha Casa Minha Vida e sua relação com os processos segregacionais e exclusão social no território. Cabe salientar que o foco principal será o programa Minha Casa Minha Vida, sendo este composto pelo Programa Nacional de Habitação Urbana (PNHU) e Programa Nacional de Habitação Rural (PNHR), contudo este trabalho concentra suas análises apenas no PNHU. Concernente aos procedimentos metodológicos, o presente estudo foi elaborado a partir da investigação em pesquisas analíticas sobre o contexto.

O conteúdo está distribuído em duas partes complementares. A primeira discute a evolução da política habitacional no Brasil. A segunda enfatiza o programa Minha Casa Minha Vida a partir da sua implementação e consequências para segregação socioespacial.

\section{A EVOLUÇÃO DA POLÍTICA HABITACIONAL NO BRASIL}

A urbanização precoce, o rápido processo de industrialização e crescimento da população brasileira no início do século XX foram os fatores principais que causaram o inchaço nas grandes cidades. Tal alargamento foi impulsionado pelo êxodo rural, no qual a população saía do campo atraída pela industrialização e ao chegar à cidade encontrava desemprego e falta de estrutura urbana. Assim, a massa mais pobre era obrigada a realizar ocupações irregulares tanto nos grandes centros quanto em seus arredores, gerando problemas relacionados a diversas áreas, dentre elas a precariedade habitacional. Conforme Bonduki (2004), boa parte dos prédios ocupados pelos trabalhadores de baixa renda daquela época eram cortiços e, portanto, ocupados por mais de uma família. O autor ainda comenta que quase $90 \%$ da população residente nas cidades, incluindo quase a totalidade dos trabalhadores e da classe média, era inquilina, inexistindo qualquer mecanismo de financiamento para aquisição da casa própria.

Levado por esse quadro de ampla demanda habitacional, por volta da década de 1940, - governo começou a definir políticas de intervenção sistemática criando uma cooperativa que seria direcionada ao financiamento da construção da casa própria, mais conhecido como Fundação Casa Popular (FCP), sendo considerado o primeiro órgão nacional voltado à habitação popular, sancionado pela lei n 9.218 de maio de 1946. Para o desenvolvimento de captação de recursos instituiu-se o Sistema Financeiro de Habitação (SFH) só na década de 1960. Tal sistema surgiu por meio da união entre o Fundo de Garantia por Tempo de Serviço (FGTS) e o Sistema Brasileiro de Poupança e Empréstimos (SPBE) que eram transferidos para o Banco Nacional de Habitação (BNH). Para Maricato (1978) a intervenção do Estado na política habitacional brasileira ocupou os espaços existentes, de modo a definir não apenas a política institucional dos setores ligados diretamente ao sistema financeiro de habitação (SFH), mas também parte do que podemos chamar de provisão informal de habitação, onde situa-se a autoconstrução, a 
favela, o loteamento clandestino, etc.

O BNH uniu-se em 1985 ao Ministério do Desenvolvimento Urbano e foi responsável por gerar 1,2 milhão de unidades para famílias de classe baixa - aquelas com rendimento menor ou igual a cinco salários mínimos. Em contrapartida, financiou 3,2 milhões de unidades para famílias com rendimento acima de cinco salários mínimos. Dessa forma, as proporções tomaram outros rumos e o que era para ser investimento social voltou-se apenas para classes já consolidadas - médias e altas. Este tipo de política pública gerou agravamento na segregação espacial e intensificou a chegada da crise econômica. A crise econômica se instalou no cenário brasileiro de maneira avassaladora, na década de 1980, e os recursos do BNH foram diminuindo chegando à escassez, levando o banco a falência. Assim, esse foi fechado em 1986 e todas suas ligações foram transferidas para a Caixa Econômica Federal (CEF).

Mais tarde, em 1994 na gestão de Itamar Franco, foi lançado o Programa Habitar Brasil e Morar, com objetivo de concluir todas as obras da gestão anterior, através de recursos do Orçamento Geral da União e do Imposto Provisório sobre as Movimentações Financeiras. No entanto, o montante de investimentos realizados não atendeu às expectativas, como consequência do contingenciamento de recursos imposto pelo Plano Real (BRASIL, 2004). Na gestão seguinte, de Fernando Henrique Cardoso (FHC), o Ministério do Planejamento apresentou um novo passo para a integração das políticas habitacionais com a implantação da Secretaria de Política Urbana em 1995, composta pelas diretorias de habitação e saneamento (MARICATO, 1998). Contudo, esse indício de integração não se deu por completo e ainda havia falta de ligação entre as políticas habitacionais e de assistência social, visto que esta organização ainda estava a cargo do Ministério do Planejamento, o que indica um caráter mais econômico da habitação.

O ano de 2000 chega como um divisor de águas na política habitacional brasileira. Em 2006 a lei $n^{\circ} 11.124 / 2005$ instituiu o Fundo Nacional de Habitação de Interesse Social (FNHIS), centralizando os recursos orçamentários dos programas de Urbanização de Assentamentos Subnormais e de Habitação de Interesse Social. Três anos depois, em 2009, é lançado o Programa Minha Casa Minha, visando construir 1 milhão de moradias, possibilitando o acesso das famílias de baixa renda a casa própria aliando-se a geração de emprego e renda. Foi implementado pelo Plano de Habitação Social (PHS), e compreende os seguintes subprogramas: o Programa Nacional de Habitação Urbana (PNHU) e o Programa Nacional de Habitação Rural (PNHR). Desde sua criação o programa disponibiliza subsídios de acordo com determinadas faixas de renda. Em 2009, por exemplo, o pacote foi delimitado em 3 faixas, sendo a primeira para atender famílias com renda mensal de até $R \$ 1.395,00$, a segunda com renda entre $R \$ 1.395,01$ e $R \$ 2.790,00$ e a terceira de $R \$ 2.790,01$ a $R \$ 4.650,00$.

\section{O PROGRAMA MINHA CASA MINHA VIDA COMO IMPULSOR DA SEGREGAÇÃO SOCIOESPACIAL}

Concebido através da proposta de aquecer a economia brasileira em momentos de crise mundial entre final do ano de 2008 e início de 2009, como também reduzir o alarmante déficit habitacional que se alargara em todo o território nacional, o Programa Minha Casa Minha Vida é considerado o maior pacote de habitação social do governo brasileiro. Desde seu lançamento os números só progrediram e as estimativas de investimento e geração de empregos foram expressivas: o investimento total do programa até 2014 foi estimado em 234 milhões de reais e geração de 1.273.071 empregos diretos e indiretos entre 2009 e 2013 (BRASIL, 2013). De acordo com o Ministério das Cidades até 2016 foram entregues mais de 2,6 milhões de residências, e beneficiou mais de 10,4 milhões de pessoas.

O sucesso do programa é visível, mas há muito o que questionar, pois o pacote provou ter outras intenções que iam além da tentativa de reduzir o déficit habitacional no Brasil. O fato de ter sido estruturado pelo Ministério da Casa Civil e Ministério da Fazenda ao invés de um órgão diretamente relacionado à questão habitacional é uma evidência do 
caráter econômico da proposta (ARANTES; FIX, 2009).

É essencial a avaliação do programa não apenas quantitativamente, com o número de domicílios construídos e empregos gerados, mas também do ponto de vista qualitativo, considerando, por exemplo, a questão da localização dos empreendimentos de habitação de interesse social e os desdobramentos no cotidiano dos moradores (MARICATO, 2009). É recorrentemente discutido na literatura sobre o tema o fenômeno da valorização de terras urbanizadas - que dispõem de infraestrutura de abastecimento de água, luz, saneamento, pavimentação, transporte público, equipamentos de educação, saúde e lazer, oferta de residências, comércio e serviços consolidados. De acordo com Maricato (1996), localizações privilegiadas em áreas urbanizadas e bem servidas de infraestrutura são alvo da valorização imobiliária e ficam disponíveis apenas para a parcela da população que possui recursos financeiros para bancá-las.

Ainda segundo essa lógica, terrenos em áreas afastadas dos centros urbanos, com precariedade de estrutura básica têm menor preço de mercado e, exatamente essas áreas têm sido alvo do interesse de construtoras e incorporadoras que produzem habitação voltada para população de baixa renda com financiamento do Programa Minha Casa Minha Vida. Maricato frisa que a concentração e segregação de pobres nas periferias em conjuntos habitacionais com localizações distantes e inadequadas geram problemas sociais de sofrimento para essas pessoas, e afeta ainda o sistema como um todo: desenvolvem-se problemas de mobilidade e "deseconomias urbanas", uma vez que "(...) quando se instala um conjunto fora da cidade, é preciso levar a cidade até o conjunto", o que gera maiores gastos públicos (MARICATO, 2009). Como consequência da exclusão imposta, a população pobre que vive em moradias distantes dos centros urbanos não têm outra opção a não ser gastar longas horas no deslocamento de casa para o trabalho e para realizar suas atividades cotidianas, além de maior despesa com o transporte público, o que afeta diretamente a sua qualidade de vida.

É inegável que o pacote teve importância em diversas instâncias no desenvolvimento recente brasileiro. O que gera preocupação é a maneira com a qual ele vem sendo manejado, destacado por Maricato (2009) como um problema estrutural dos programas habitacionais no país. O combate ao déficit, que deveria ser o problema principal a ser solucionado, ainda divide atenção com a especulação imobiliária. Além disso, observase também forte desarticulação do projeto com outros tipos de política urbana e social.

\section{CONCLUSÕES}

No Brasil difundiu-se o modelo de implantação de conjuntos habitacionais para populações de baixa renda nas periferias das cidades, em locais em que a terra é mais desvalorizada em relação àquelas presentes nos centros urbanos propriamente ditos (MARICATO, 1998). Assim como defende Maricato, entende-se como necessário pensar na habitação como um direito e não como um produto mercantil e desenvolver o seu potencial como estratégia para promover espaços mais heterogêneos socialmente em contraposição aos modelos homogêneos e segregadores que separam territorialmente camadas da população de acordo com sua renda.

Nesse sentido, o fortalecimento da Função Social da Propriedade, estabelecida por lei na Constituição Federal de 1988 e endossado no Estatuto da Cidade, publicado em 2001, pode ser um caminho para o combate ao padrão excludente e segregador da urbanização no Brasil. A ocupação de imóveis vagos e a localização da população de baixa renda em áreas já urbanizadas é uma alternativa a intensificação do modelo de periferização em curso e todos os seus efeitos perversos previamente mencionados.

\section{REFERÊNCIAS}

ARANTES, P. F.; FIX, M. Como o governo Lula pretende resolver o problema de habitação. Disponível em: 
<http://www.unmp.org.br/index.php?option=com_content\&view=article\&id=297:como-ogoverno-lula-pretende-resolver-o-problema-da-habitacao\&catid=40:materiais-sobre-politicade-habitacao\&ltemid=68> . Acesso em: 1 set. 2017.

BONDUKI, N. Origens da habitação social no Brasil. Arquitetura moderna, lei do inquilinato e difusão da casa própria. $4^{a}$ Edição, São Paulo, 2004.

BRASIL. Decreto-Lei $\mathbf{n}^{\circ}$ 9.777, de 6 de setembro de 1946. Estabelece bases financeiras para a "Fundação da Casa Popular e dá outras providências. Disponível em: <http://www.planalto.gov.br/ccivil_03/decreto-lei/1937- 1946/Del9777.htm>. Acesso em 03/09/2017.

Ministério das Cidades. Secretaria Nacional de Habitação. Plano Nacional de Habitação. Brasília, 2004.

Ministério das Cidades. Secretaria de Assuntos Estratégicos da Presidência da República. Programa Minha Casa, Minha Vida - Avanços socioeconômicos. Brasília, 2013.

MARICATO, E. Política Habitacional no Regime Militar. Vozes: Petrópolis, 1987.

Metrópole na Periferia do Capitalismo. Hucitec: São Paulo, 1996.

Política urbana e habitação social: um assunto pouco importante para o Governo FHC. Revista Praga, São Paulo: Hucitec, vol. 1, n. 6, 1998.

out. 2009 É preciso repensar o modelo. Arquitetura e Urbanismo, São Paulo, n. 186

O "Minha Casa" é um avanço, mas segregação urbana fica

intocada. Carta Maior, 2009. Disponível em:

<http://www.cartamaior.com.br/?/Editoria/Politica/O-Minha-Casa-e-um-avancomas-segregacao- urbana-fica-intocada/4/15160>. Acesso em: 3 set. 2017. 